\title{
Gastroesophageal reflux in cystic fibrosis across the age spectrum
}

\author{
Frederick W. Woodley ${ }^{1,2}$, Don Hayes $\mathrm{Jr}^{2,3}$, Benjamin T. Kopp ${ }^{2,3}$, Melissa Moore-Clingenpeel ${ }^{4}$, Rodrigo \\ Strehl Machado ${ }^{5}$, Christopher J. Nemastil ${ }^{3}$, Sudarshan Jadcherla ${ }^{2,6}$, Carlo Di Lorenzo ${ }^{1,2}$, Ajay Kaul ${ }^{7,8}$, \\ Hayat Mousa, ${ }^{9}$
}

${ }^{1}$ Center for Motility Disorders, Division of Gastroenterology, Hepatology and Nutrition, Nationwide Children's Hospital, Columbus, OH, USA; ${ }^{2}$ Department of Pediatrics, The Ohio State University College of Medicine, Columbus, OH, USA; ${ }^{3}$ Division of Pulmonary Medicine, ${ }^{4}$ Center for Biostatistics, Nationwide Children's Hospital, Columbus, OH, USA; ${ }^{5}$ Universidad Federal de Sao Paulo, Sao Paulo, Brazil; ${ }^{6}$ Division of Neonatology, Nationwide Children's Hospital, Columbus, OH, USA; ${ }^{7}$ Division of Gastroenterology, Cincinnati Children's Hospital Medical Center, Cincinnati, OH, USA; ${ }^{8}$ Department of Pediatrics, University of Cincinnati College of Medicine, Cincinnati, OH, USA; ${ }^{9}$ Division of Gastroenterology, Rady Children's Hospital, San Diego, CA, USA; ${ }^{10}$ Department of Pediatrics, University of California-San Diego, San Diego, CA, USA

Contributions: (I) Conception and design: FW Woodley, D Hayes Jr, BT Kopp, RS Machado, CJ Nemastil, S Jadcherla, C Di Lorenzo, A Kaul, H Mousa; (II) Administrative support: FW Woodley, CJ Nemastil; (III) Provision of study materials or patients: FW Woodley, A Kaul, H Mousa; (IV) Collection and assembly of data: FW Woodley, CJ Nemastil; (V) Data analysis and interpretation: FW Woodley, RS Machado, M MooreClingenpeel, CJ Nemastil; (VI) Manuscript writing: All authors; (VII) Final approval of manuscript: All authors.

Correspondence to: Frederick W. Woodley. Center for Motility Disorders, Division of Gastroenterology, Hepatology and Nutrition, Nationwide Children's Hospital, Columbus, OH, USA; Department of Pediatrics, The Ohio State University College of Medicine, Columbus, OH, USA. Email: frederick.woodley@nationwidechildrens.org.

Background: Scientific advances have improved longevity in cystic fibrosis (CF) patients and many of these patients can expect to experience age-related gastrointestinal co-morbidities. We aimed to assess the extent to which age might impact gastroesophageal reflux (GER) in patients with CF.

Methods: Our esophageal pH-multichannel intraluminal impedance monitoring database was searched for tracings belonging to CF patients $\geq 2$ years old without prior fundoplication and not taking anti-reflux medications immediately prior (within 7 days) and during the study. Tracings were retrospectively analyzed; Impedance and $\mathrm{pH}$ variables were evaluated with respect to age and pulmonary function.

Results: Twenty-eight patients were enrolled; 16 children (3.1-17.7 years) and 12 adults (18.2-48.9 years). Among $\mathrm{pH}$ probe parameters, correlation analysis showed DeMeester score $(\mathrm{P}=0.011)$ and number of acid reflux events lasting $>5$ minutes $(\mathrm{P}=0.047)$ to be significantly correlated with age. Age was not significantly correlated with any of the impedance parameters. Age was negatively correlated with baseline impedance (BI) in the distal esophagus $(\mathrm{r}=-0.424, \mathrm{P}=0.023)$ and $\mathrm{BI}$ was negatively correlated with several $\mathrm{pH}$ parameters, including reflux index $(\mathrm{r}=-0.553, \mathrm{P}=0.002)$, number of total acid reflux events $(\mathrm{r}=-0.576, \mathrm{P}=0.001)$, number of acid reflux events lasting $>5$ minutes $(r=-0.534, \mathrm{P}=0.003)$, and DeMeester score $(\mathrm{r}=-0.510, \mathrm{P}=0.006)$. Pulmonary function (percent predicted forced expiratory volume in one minute; $\mathrm{ppFEV}_{1}$ ) was negatively correlated with age $(\mathrm{r}=-0.494, \mathrm{P}=0.0007)$. The interaction of age and $\mathrm{ppFEV}_{1}$ and any of the reflux parameters, however, was not significant $(\mathrm{P}>0.05)$; the strongest evidence for an interaction was found for the number of acid reflux events reaching the proximal esophagus, but this interaction still did not reach statistical significance $(\mathrm{P}=0.070)$.

Conclusions: In a small cohort, we found evidence that age may be associated with increased acid exposure and that both age and increased acid exposure are associated with reduced BI in the distal esophagus. The negative relationship between pulmonary function and age in our cohort is not related to GER. This pilot study supports the need for esophageal assessment and treatment of GER as standard components of clinical care for an aging CF population. 
Keywords: Cystic fibrosis (CF); gastroesophageal reflux (GER); age; pH-impedance monitoring; esophageal pH monitoring and multichannel intraluminal impedance (EPM-MII)

Received: 08 March 2019; Accepted: 13 August 2019; Published: 16 September 2019.

doi: $10.21037 / \operatorname{tgh} .2019 .08 .11$

View this article at: http://dx.doi.org/10.21037/tgh.2019.08.11

\section{Introduction}

Cystic fibrosis (CF) is a common autosomal recessive lethal genetic disease, affecting 30,000 patients in the United States and 70,000 worldwide (1). The disease is caused by a mutation in the CF transmembrane conductance regulator (CFTR) gene that leads to abnormal chloride transport in multiple organ systems. Organ systems affected by the disease include respiratory, gastrointestinal, and urogenital. Patients with CF produce abnormal secretions, which is difficult to remove from the respiratory and gastrointestinal tracts. Pulmonary deterioration bronchiectasis and chronic infection is the leading cause of morbidity and mortality (2).

Advances in technology and pharmaceutical therapies that assist mucociliary clearance of the lower airways of the lung have resulted in significant improvement in the life expectancy of patients with CF. Consequently, patients with $\mathrm{CF}$ are at risk for co-morbidities due to aging. Among these co-morbidities is gastroesophageal reflux (GER). In healthy populations, previous research shows agerelated alterations that include reduced salivary flow and bicarbonate secretion, increased likelihood of hiatal hernia development predisposing patients to reduced pressure in the lower esophageal sphincter (LES), decreased abdominal LES length, and reduced esophageal motility, all of which can result in increased esophageal exposure to gastric contents (3). Other variables known to contribute to age-related GER disease include a deteriorating antireflux barrier, atypical esophageal clearance, reduced mucosal resistance, and delays in gastric emptying (4). Since pediatric and adult patients with $\mathrm{CF}$ are at higher risk for increased GER $(5,6)$, and GER is known to worsen with age (7-9), we performed a study to assess the potential effect of age on GER in CF. Using combined esophageal $\mathrm{pH}$ monitoring and multichannel intraluminal impedance (EPM-MII) monitoring and correlation analysis, we assessed the extent to which age is associated with GER in patients with CF.

\section{Methods}

\section{Patients}

Upon approval by the local Institutional Review Board (IRB08-00247), we searched our EPM-MII database for CF patients who: (I) were $\geq 2$ years of age; (II) not taking anti-GER medications; (III) had not had a lung transplant; and (IV) did not receive a fundoplication prior to testing. Inclusion required a diagnosis of CF (via sweat chloride or genetic testing) and the absence of anti-reflux medication (proton pump inhibitors, histamine-2 receptor antagonists, and prokinetics) use for 7, 5, and 2 days, respectively, prior to the study (10).

\section{Esophageal pH monitoring (EPM)}

EPM-MII software provided by Sandhill Scientific (Highlands Ranch, Colorado) was used to generate a report for each patient. With EPM, we measured: (I) reflux index; (II) number of acid events; (III) mean duration of acid events; (IV) number of events lasting $>5$ minutes; and (V) DeMeester score. The reflux index is the percentage of total study time below $\mathrm{pH}$ 4. The DeMeester score is a composite of several acid exposure parameters (11).

\section{EPM-MII tracing analysis}

\section{GER episodes}

Impedance tracings were comprised of six impedance waveform channels, where channel 1 denotes intraluminal activity in the most proximal esophagus (Z1) and channel 6 denotes intraluminal activity in the most distal esophagus (Z6) (Figure 1). The start time of an individual EPM-MIIdetected GER episode was signaled when the impedance waveform in channel 6 dropped to $50 \%$ of baseline. The stop time of an individual GER episode was then signaled when the impedance waveform in channel 6 ascended to 


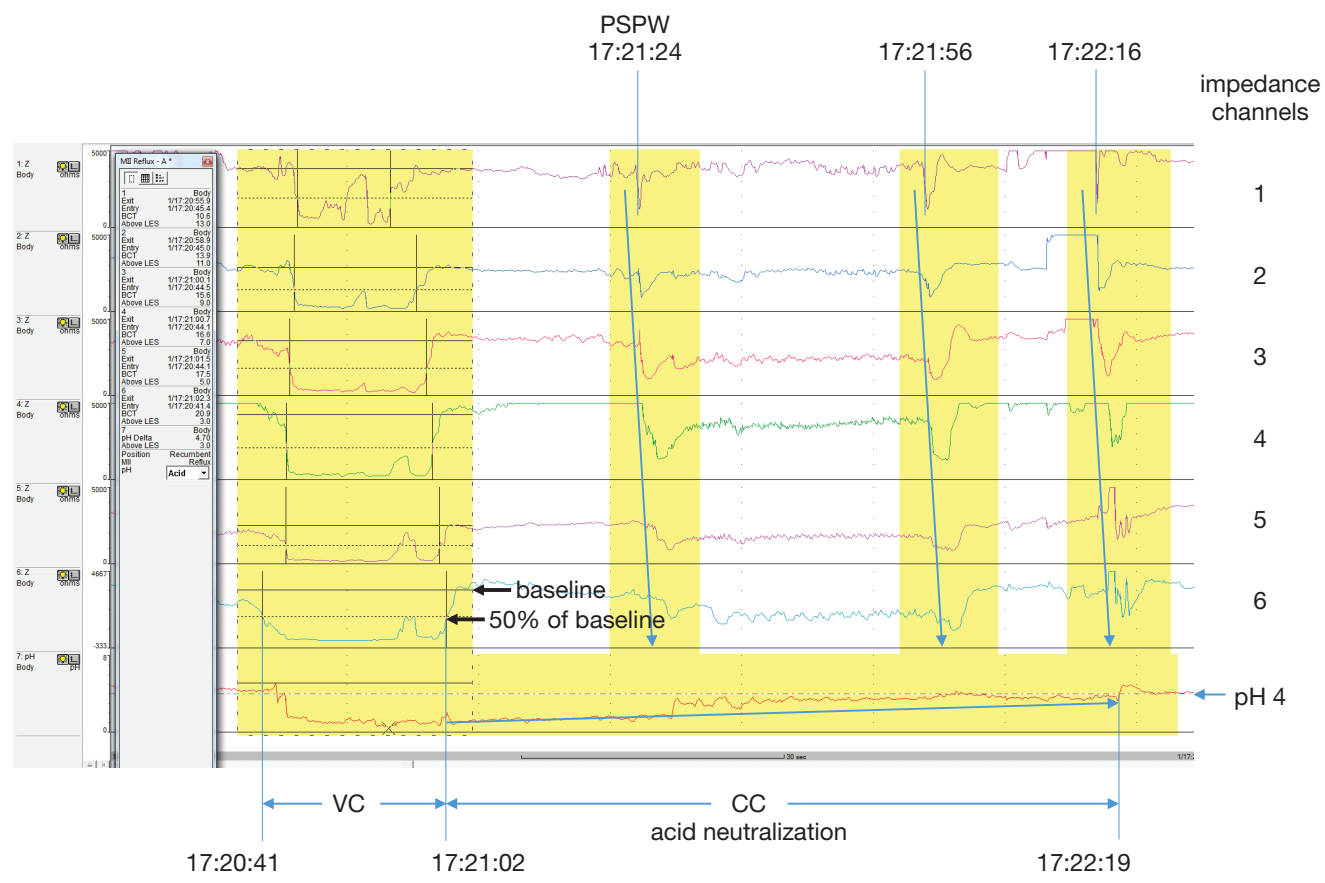

Figure 1 Combined esophageal $\mathrm{pH}$ monitoring and multichannel intraluminal impedance (EPM-MII) tracing illustrating an acid gastroesophageal reflux (AGER) event. The volume clearance (VC) component $(17: 20: 41 \rightarrow 17: 21: 02)$ is followed within 30 seconds by a post-reflux swallow-induced peristaltic wave (PSPW) (17:21:24) that occurred during the beginning of chemical clearance (CC). The AGER episode is eventually cleared at 17:22:19 by a clearing swallow (17:22:16). VC lasted 21 seconds and acid neutralization during CC (AN-CC) lasted 1 minute 17 seconds.

$\geq 50 \%$ of baseline. The only GER events recorded were those that lasted $\geq 5$ seconds and ascended proximally to channel 5 or above. GER events were tagged as being acidic (AGER) when the $\mathrm{pH}$ electrode, located at the distal end of the impedance catheter, dropped to below $\mathrm{pH} 4$ at any time during the impedance-detected event. Non-acidic GER (NAGER) events are impedance-detected episodes of GER during which the $\mathrm{pH}$ in the distal esophagus remains at or above $\mathrm{pH} 4$ (12). Events occurring during feeding were not recorded.

With combined EPM-MII monitoring, we measured: (I) number of AGER, NAGER, and total GER; (II) number of AGER, NAGER, and total GER that reached channel 2 (considered proximal events); (III) median bolus contact time (BCT); and (IV) percent BCT (percent of total study time during which the esophageal mucosa was exposed to gastric content).

\section{Assessing chemical clearance (CC) efficiency}

Two-phase AGER episodes were used to assess the efficiency of acid neutralization during chemical clearance
(AN-CC) as previously described (10,13). A two-phase AGER episode is an acidic GER episode during which both the volume clearance (VC) and CC components are detected by EPM-MII monitoring (Figure 1). Briefly, for each two-phase AGER episode, CC was defined as the duration of time during which the esophageal mucosa remained acidified $(\mathrm{pH}<4)$ after $\mathrm{VC}$ was completed. A median duration (seconds) of acid neutralization during CC was calculated for each patient $(10,13)$.

Additionally, a post-reflux swallow-induced peristaltic wave (PSPW) index was calculated by: (I) counting the number of impedance-detectable GER episodes that were followed within 30 seconds by a swallow-induced peristaltic wave denoting a swallow; and (II) dividing this number by the total number of impedance-detected GER episodes. Figure 1 illustrates an acid GER event followed within 30 seconds by a swallow. A mean PSPW Index was calculated for each patient (14).

\section{Assessing the proximal extent of GER}

The number of GER episodes that reached the proximal 
Table 1 Patient demographics

\begin{tabular}{lc}
\hline Demographic & $\mathrm{N}$ \\
\hline Patients & 28 \\
Age, median yrs (range) & $16.9(3.1-48.9)$ \\
Sex, M/F & $12 / 16$ \\
Race, CA/AA & $28 / 0$ \\
Genotype $^{\dagger}$ & $15: 10: 2: 1$ \\
\hline
\end{tabular}

${ }^{\dagger}$, F508del homozygous:F508del heterozygous:other:not determined. CA, Caucasian; AA, African American.

esophagus was recorded for AGER and NAGER episodes. GER episodes were considered "proximal" when they extended into or above channel 2.

\section{Baseline impedance (BI) measurements}

BI measurements were made in both channel 1 and channel 6. For each patient, a mean of means was calculated for each of the two channels using a modified version of the method described by Martinucci and colleagues (15). For each patient, one minute measurements were recorded at three time points (around 1AM, 2AM, and 3AM) to avoid swallows, GER events, and drops in $\mathrm{pH}$. An average was then calculated for each patient. To determine the number of children and adults who had abnormal BI in the distal esophagus (channel 6), reference cut-off values were set at $1,818 \Omega$ for children (16) and 2,292 $\Omega$ for adults (17), respectively. The BI reference value for children was established in our laboratory, derived from tracings for a group of symptomatic children who were symptom association probability (SAP)-negative and had acid reflux indices in the physiological range $(<3 \%)(13)$.

\section{Pulmonary function tests as a function of age}

Testing results for percent predicted forced expiratory volume in one second $\left(\mathrm{ppFEV}_{1}\right)$ were recorded during periods 6 months before and 6 months after the date of each EPM-MII study. The ppFEV ${ }_{1}$ is the volume of exhaled breath that can be forced out in the first second following a deep inspiratory breath (18). For each patient, an average was generated from data collected on multiple testing dates. We assessed the potential impact of the interaction of age and GER (EPM-MII and pH only) on ppFEV $\mathrm{p}_{1}$

\section{Statistical analysis}

The non-parametric Spearman's rank-order correlation coefficient was used to measure the strength and direction of association between the variables. Linear regression was used to evaluate the interaction between GER and age on $\operatorname{ppFEV}_{1}$. Odds ratio analysis was used to determine whether adult CF patients were more likely than children with CF to have abnormal BI. Statistical significance was established at $\mathrm{P}<0.05$.

\section{Results}

\section{Enrollment}

Sixty-two patients with CF were identified; 30 children (48\%) and 32 adults (52\%). Among children, 14 were excluded; 4 for fundoplication, 4 for anti-reflux medications, 4 for anti-reflux medications plus fundoplication, and 2 under age 2 years. Among adults, 20 were excluded; 5 for fundoplication, 10 for anti-GER medications, and 5 for anti-GER medications plus fundoplication. Final enrollment included 16 children (ages 3.1 to 17.7 years) and 12 adults (ages 18.2 to 48.9 years). General patient demographics are briefly highlighted in Table 1. Enrolled subjects presented with symptoms that included cough, regurgitation, heartburn, choking, abdominal pain, decline in pulmonary function tests, wheezing, chest pain, and gagging.

\section{Association between age and GER}

When considering age and EPM metrics, all of the $\mathrm{pH}$ indicators increased with age, but only DeMeester score $(\mathrm{r}=0.47, \mathrm{P}=0.011)$ and number of $\mathrm{pH}$ events lasting $>5$ minutes $(\mathrm{r}=0.38, \mathrm{P}=0.047)$ increased significantly (Table 2). When age and EPM-MII metrics were examined, all parameters (with the exception of NAGER metrics) increased with age, but none achieved statistical significance. Non-acid reflux (NAGER) parameters declined with age, but not significantly. Age was not associated with either of the chemical clearance parameters (AN-CC and PSPW) or with nadir $\mathrm{pH}$.

\section{Effects of age and GER on lung function}

$\operatorname{ppFEV}_{1}$ measures were not available for four of the children and one of the adults. Correlation coefficients showed $\mathrm{ppFEV}_{1}$ significantly worsened with age $(\mathrm{r}=-0.494$, $\mathrm{P}=0.0007)$. Assessments of the interaction between age and GER on ppFEV $_{1}$ showed that age does not significantly 
Table 2 Association between age and various parameters

\begin{tabular}{|c|c|c|}
\hline Parameter & rho & $P$ value \\
\hline \multicolumn{3}{|l|}{ EPM } \\
\hline Reflux index & 0.29 & 0.14 \\
\hline Events & 0.16 & 0.41 \\
\hline Mean duration (sec) & 0.27 & 0.16 \\
\hline Longest AGER (min) & 0.18 & 0.35 \\
\hline Events $>5 \mathrm{~min}$ & 0.38 & $0.047^{*}$ \\
\hline DeMeester score & 0.47 & $0.011^{*}$ \\
\hline \multicolumn{3}{|l|}{ EPM-MII } \\
\hline GER & 0.20 & 0.30 \\
\hline AGER & 0.29 & 0.13 \\
\hline NAGER & -0.11 & 0.57 \\
\hline$\% \mathrm{BCT}$ & 0.21 & 0.29 \\
\hline Median BCT (sec) & 0.29 & 0.13 \\
\hline Proximal GER & 0.49 & 0.34 \\
\hline Proximal AGER & 0.28 & 0.15 \\
\hline Proximal NAGER & -0.04 & 0.85 \\
\hline \multicolumn{3}{|l|}{$\mathrm{CC}, \mathrm{pH}$ nadir, $\mathrm{ppFEV}_{1}$} \\
\hline $\mathrm{AN}-\mathrm{CC}$ & -0.02 & 0.83 \\
\hline PSPW & -0.037 & 0.85 \\
\hline $\mathrm{pH}$ nadir & 0.09 & 0.65 \\
\hline ppFEV $_{1}$ & -0.494 & $0.0007^{\star *}$ \\
\hline
\end{tabular}

${ }^{*} \mathrm{P}<0.05,{ }^{*} \mathrm{P}<0.001$. EPM, esophageal $\mathrm{pH}$ monitoring; MII, multichannel intraluminal impedance; GER, gastroesophageal reflux; AGER, acid GER; NAGER, non-acid GER; BCT, bolus contact time; rho, Spearman coefficient; CC, chemical clearance; AN-CC, acid neutralization during chemical clearance; PSPW, post-reflux swallow-induced peristaltic wave; ppFEV $_{1}$, percent predicted forced expiratory volume in one minute; $\mathrm{pH}$ nadir, lowest median $\mathrm{pH}$. CC was assessed using both the AN-CC and PSPW.

modify the association between GER and $\operatorname{ppFEV}_{1}$ (Table 3).

\section{Association between age and BI}

Correlation analysis demonstrated that, while the association between age and proximal BI was not statistically significant $(\mathrm{r}=-0.283, \mathrm{P}=0.114)$, there was a significant negative association between age and $\mathrm{BI}$ in the distal esophagus ( $\mathrm{r}=-0.424, \mathrm{P}=0.023$ ) (Table 4). Distal BI was also
Table 3 Interaction of age and $\mathrm{ppFEV}_{1}$ and GER

\begin{tabular}{ll}
\hline Parameter & P value \\
\hline EPM & \\
Reflux index & 0.9248 \\
Events & 0.9363 \\
Mean duration (sec) & 0.1653 \\
Longest AGER (min) & 0.7346 \\
Events $>5$ min & 0.8371 \\
DeMeester score & 0.7657 \\
EPM-MII & \\
AGER & 0.2464 \\
NAGER & 0.1384 \\
GER & 0.5524 \\
\%BCT & 0.1704 \\
Median BCT & 0.4589 \\
Proximal GER & 0.1340 \\
Proximal AGER & $0.0699^{\dagger}$ \\
Proximal NAGER & 0.8360 \\
\hline
\end{tabular}

${ }^{\dagger}$, approaching statistical significance. GER, gastroesophageal reflux; $p p F E V_{1}$, percent predicted forced expiratory volume in one minute; EPM, esophageal pH monitoring; AGER, acid GER; MII, multichannel intraluminal impedance; NAGER, non-acid GER; BCT, bolus contact time.

Table 4 Association of distal baseline impedance with age

\begin{tabular}{lcc}
\hline Parameter & rho & P value \\
\hline Proximal baseline impedance & -0.283 & 0.114 \\
Distal baseline impedance & -0.424 & $0.023^{*}$ \\
\hline
\end{tabular}

${ }^{*} \mathrm{P}<0.05$. rho, Spearman coefficient.

negatively associated with several EPM parameters (Table 5). Eight of 16 children (50\%) and 11 of 12 adults (91.7\%) had abnormal baseline values in the distal esophagus. Odds ratio analysis showed that adult CF patients are 11.0-times (95\% CI: $1.14-106.43, \mathrm{P}=0.0384)$ more likely than children to have an abnormally low BI in the distal esophagus.

\section{Discussion}

Correlation analyses showed that age does not have a significant impact on the majority of EPM, nor on any 
Table 5 Association of distal baseline impedance with $\mathrm{pH}$ parameters

\begin{tabular}{lcl}
\hline Parameter & rho & P value \\
\hline Reflux index & -0.553 & $0.002^{\star \star}$ \\
Events & -0.576 & $0.001^{\star \star}$ \\
Mean duration (sec) & -0.106 & 0.590 \\
Longest AGER (min) & -0.238 & 0.222 \\
Events >5 min & -0.534 & $0.003^{\star \star}$ \\
DeMeester score & -0.510 & $0.006^{\star}$ \\
\hline
\end{tabular}

${ }^{*} \mathrm{P}<0.05,{ }^{* \star} \mathrm{P}<0.005$. GER, gastroesophageal reflux; AGER, acid GER.

of the EPM-MII parameters. The DeMeester score and the number of acid events lasting $>5$ minutes were the exceptions. Because the DeMeester score is a composite score that considers several important $\mathrm{pH}$ parameters (reflux index, total number of acid GER events, number of events lasting $>5$ minutes, and the longest acid GER event) (11), it provides a comprehensive assessment of esophageal acid exposure. The failure of other correlations to achieve statistical significance is likely due to variability among both children and adults with CF and to the small sample size (19), combined with the fact that GER is so prevalent among children with CF (6). For these reasons, increases in GER severity due to aging are likely to be statistically undetectable in small cohorts. It is important to note that the significant association that age has with events lasting $>5$ minutes and with DeMeester score are important observations nonetheless, providing evidence that age is associated with increased acid exposure in patients with CF.

$\mathrm{BI}$ is related to acid exposure. Farre and colleagues showed that esophageal BI drops and remains low following acid perfusion (20). Kessing and colleagues showed that distal BI was significantly lower in subjects with pathological acid exposure compared to subjects with physiological acid exposure or to healthy volunteers (21). Pilic and colleagues (22) found that increased acid exposure and bolus exposure time were correlated with lower distal BI. Impaired mucosal integrity is detected when dilated intercellular spaces collect ion-rich liquids, resulting in increased conductance and reduced impedance (23-29). The present study found that age is negatively correlated with distal BI in CF. It also demonstrated that distal BI is negatively related to several of the $\mathrm{pH}$ parameters. These findings, combined with our results showing that adult
CF patients are 11-times more likely to have abnormally low distal BI, suggest that older CF patients are prone to mucosal injury due to increased acid exposure, and therefore should continue to be monitored and treated appropriately for GER.

It has been suggested that GER negatively impacts pulmonary function in patients with CF (30-35). We investigated the possible association of GER and age on pulmonary function in all subjects for whom data were available. Our study showed that GER did not modify the association between age and $\operatorname{ppFEV}_{1}$. This is an important observation because it suggests that, at least in our cohort, the inverse relationship between lung function and age does not appear to be related to GER.

This study has several limitations. First, our method for BI measurement (i.e., 1-minute epochs) could be a possible limitation. To date, an optimal window of time for obtaining a BI value that defines the esophageal mucosa has not been determined, and it has been suggested that possible bias selection could be introduced in studies that either exclude or include belches, swallows, or GER episodes (36). Ummarino and colleagues compared different time intervals with 24-hour analysis that either included or excluded burps, swallows, and bolus GER and found no significant difference $(36,37)$. Our use of 1-minute samples is therefore not likely to be a significant consideration. Second, our choice of a cutoff value used to identify children with abnormal distal BI may not be ideal, because the tracings used to derive this value were generated from children who were symptomatic; however, the cutoff value at the $5^{\text {th }}$ percentile $(1,818 \Omega)$ is likely to be a reasonably accurate estimate because enrolled patients had reflux indices within the physiological range (i.e., RI $<3 \%$ ), and were likely therefore to have normal esophageal mucosa. The study would have benefited from having endoscopy data to assess mucosal integrity across the age spectrum and to validate our use of the $1,818 \Omega$ cut-off value (16) for children with CF and the 2,292 $\Omega$ cut-off value (17) for adults with CF. Third, our use of the DeMeester score may have been a limitation of this study. Unlike the Boix-Ochoa composite score (38), the DeMeester score has not been validated in children; however, two groups recently found that the correlation of the DeMeester score with Boix-Ochoa score was very high $(\mathrm{r}=0.94, \mathrm{P}<0.01$ and $\mathrm{r}=0.99, \mathrm{P}<0.01$, respectively) $(39,40)$. We chose to use the DeMeester score to allow for comparison between children and adults. The study would have also benefited from having older subjects (i.e., > 50 years), in whom we suspect the impact of aging on 
GER would be even more pronounced. Finally, our study is limited by its small cohort and lack of a control group. The availability of retrospective studies can be limited by the large numbers of patients with CF who are on a PPI at the time of their study (41); therefore, larger prospective multicenter collaborative studies are needed to increase the size of the cohort.

This study provides evidence suggesting that patients with CF are at increased risk for acid exposure with advancing age. It supports an aging model where increased acid exposure is associated with impaired mucosal integrity. The evaluation and treatment of GER is indicated for the older CF patient population, particularly those patients with declining pulmonary function who require lung transplantation. With gastric dysfunction and impaired motility being common in CF patients before and after lung transplant, previous reports have found fundoplication in the CF lung transplant recipient to be an important treatment option, demonstrating another CF population at increased risk for GER (2,42-44). Further research is necessary to address these important issues related to GER in order to reduce the co-morbidities related to aging and to guide clinical management of the older CF population.

\section{Acknowledgments}

The authors wish to thank Drs. Karen McCoy and Alpa Patel for helping with patient recruitment and data acquisition.

\section{Footnote}

Conflicts of Interest: The authors have no conflicts of interest to declare.

Ethical Statement: IRB approval was granted for our retrospective design (IRB08-00247). Consent to participate was not possible because of the design of the study without intervention. The authors are accountable for all aspects of the work in ensuring that questions related to the accuracy or integrity of any part of the work are appropriately investigated and resolved.

\section{References}

1. O'Sullivan BP FS. Cystic Fibrosis. Lancet 2009;373:1891-904.

2. Robinson NB, DiMango E. Prevalence of gastroesophageal reflux in cystic fibrosis and implications for lung disease. Ann Am Thorac Soc 2014;11:964-8.

3. Achem SR, DeVault KR. Gastroesophageal reflux disease and the elderly. Gastroenterol Clin North Am 2014;43:147-60.

4. Richter JE. Gastroesophageal reflux disease in the older patient: presentation, treatment, and complications. Am J Gastroenterol 2000;95:368-73.

5. Blondeau K, Dupont LJ, Mertens V, et al. Gastrooesophageal reflux and aspiration of gastric contents in adult patients with cystic fibrosis. Gut 2008;57:1049-55.

6. Blondeau K, Pauwels A, Dupont L, et al. Characteristics of gastroesophageal reflux and potential risk of gastric content aspiration in children with cystic fibrosis. J Pediatr Gastroenterol Nutr 2010;50:161-6.

7. Castell DO. Esophageal disorders in the elderly. Gastroenterol Clin North Am 1990;19:235-54.

8. Ferriolli E, Oliveira RB, Matsuda NM, et al. Aging, esophageal motility, and gastroesophageal reflux. J Am Geriatr Soc 1998;46:1534-7.

9. Orr WC, Chen CL. Aging and neural control of the GI tract: IV. Clinical and physiological aspects of gastrointestinal motility and aging. Am J Physiol Gastrointest Liver Physiol 2002;283:G1226-31.

10. Woodley FW, Machado RS, Hayes D Jr, et al. Children with cystic fibrosis have prolonged chemical clearance of acid reflux compared to symptomatic children without cystic fibrosis. Dig Dis Sci 2014;59:623-30.

11. Johnson LF, Demeester TR. Twenty-four-hour $\mathrm{pH}$ monitoring of the distal esophagus. A quantitative measure of gastroesophageal reflux. Am J Gastroenterol 1974;62:325-32.

12. Sifrim D, Castell D, Dent J, et al. Gastro-oesophageal reflux monitoring: review and consensus report on detection and definitions of acid, non-acid, and gas reflux. Gut 2004;53:1024-31.

13. Woodley FW, Machado R, Di Lorenzo C, et al. Chemical clearance in infants and children with Acid reflux in the physiologic range. J Pediatr Gastroenterol Nutr 2015;60:783-6.

14. Frazzoni M, Manta R, Mirante VG, et al. Esophageal chemical clearance is impaired in gastro-esophageal reflux disease--a 24-h impedance-pH monitoring assessment. Neurogastroenterol Motil 2013;25:399-406, e295.

15. Martinucci I, de Bortoli N, Savarino E, et al. Esophageal baseline impedance levels in patients with pathophysiological characteristics of functional heartburn. Neurogastroenterol Motil 2014;26:546-55. 
16. Woodley FW, Machado RS, Di Lorenzo C, et al. Reference values for proximal and distal baseline impedance from infants and children with esophageal acid exposure in the physiological range. J Pediatr Gastroenterol Nutr 2018;67:S161-2.

17. Frazzoni M, Savarino E, de Bortoli N, et al. Analyses of the Post-reflux Swallow-induced Peristaltic Wave Index and Nocturnal Baseline Impedance Parameters Increase the Diagnostic Yield of Impedance-pH Monitoring of Patients With Reflux Disease. Clin Gastroenterol Hepatol 2016;14:40-6.

18. Miller MR, Hankinson J, Brusasco V, et al. Standardisation of spirometry. Eur Respir J 2005;26:319-38.

19. Button KS, Ioannidis JP, Mokrysz C, et al. Power failure: why small sample size undermines the reliability of neuroscience. Nat Rev Neurosci 2013;14:365-76.

20. Farre R, Blondeau K, Clement D, et al. Evaluation of oesophageal mucosa integrity by the intraluminal impedance technique. Gut 2011;60:885-92.

21. Kessing BF, Bredenoord AJ, Weijenborg PW, et al. Esophageal acid exposure decreases intraluminal baseline impedance levels. Am J Gastroenterol 2011;106:2093-7.

22. Pilic D, Hankel S, Koerner-Rettberg C, et al. The role of baseline impedance as a marker of mucosal integrity in children with gastro esophageal reflux disease. Scand J Gastroenterol 2013;48:785-93.

23. Caviglia R, Ribolsi M, Maggiano N, et al. Dilated intercellular spaces of esophageal epithelium in nonerosive reflux disease patients with physiological esophageal acid exposure. Am J Gastroenterol 2005;100:543-8.

24. Barlow WJ, Orlando RC. The pathogenesis of heartburn in nonerosive reflux disease: a unifying hypothesis. Gastroenterology 2005;128:771-8.

25. Tobey NA, Argote CM, Vanegas XC, et al. Electrical parameters and ion species for active transport in human esophageal stratified squamous epithelium and Barrett's specialized columnar epithelium. Am J Physiol Gastrointest Liver Physiol 2007;293:G264-70.

26. Orlando RC, Bryson JC, Powell DW. Mechanisms of $\mathrm{H}+$ injury in rabbit esophageal epithelium. Am J Physiol 1984;246:G718-24.

27. Tobey NA, Carson JL, Alkiek RA, et al. Dilated intercellular spaces: a morphological feature of acid reflux-damaged human esophageal epithelium. Gastroenterology 1996;111:1200-5.

28. Orlando LA, Orlando RC. Dilated intercellular spaces as a marker of GERD. Curr Gastroenterol Rep 2009;11:190-4.
29. Ravi K, Katzka DA. Esophageal Impedance Monitoring: Clinical Pearls and Pitfalls. Am J Gastroenterol 2016;111:1245-56.

30. Gustafsson PM, Fransson SG, Kjellman NI, et al. Gastrooesophageal reflux and severity of pulmonary disease in cystic fibrosis. Scand J Gastroenterol 1991;26:449-56.

31. Palm K, Sawicki G, Rosen R. The impact of reflux burden on Pseudomonas positivity in children with cystic fibrosis. Pediatr Pulmonol 2012;47:582-7.

32. Button BM, Roberts S, Kotsimbos TC, et al. Gastroesophageal reflux (symptomatic and silent): a potentially significant problem in patients with cystic fibrosis before and after lung transplantation. J Heart Lung Transplant 2005;24:1522-9.

33. Ledson MJ, Tran J, Walshaw MJ. Prevalence and mechanisms of gastro-oesophageal reflux in adult cystic fibrosis patients. J R Soc Med 1998;91:7-9.

34. Vic P, Tassin E, Turck D, et al. Frequency of gastroesophageal reflux in infants and in young children with cystic fibrosis. Arch Pediatr 1995;2:742-6.

35. Stringer DA, Sprigg A, Juodis E, et al. The association of cystic fibrosis, gastroesophageal reflux, and reduced pulmonary function. Can Assoc Radiol J 1988;39:100-2.

36. Salvatore S, Salvatoni A, Van Berkel M, et al. Esophageal impedance baseline is age dependent. J Pediatr Gastroenterol Nutr 2013;57:506-13.

37. Ummarino D, Salvatore S, Hauser B, et al. Baseline esophageal impedance according to different time intervals. Dis Esophagus 2013;26:582-6.

38. Boix-Ochoa J, Lafuenta JM, Gil-Vernet JM. Twentyfour hour exophageal $\mathrm{pH}$ monitoring in gastroesophageal reflux. J Pediatr Surg 1980;15:74-8.

39. Lupu VV, Ignat A, Paduraru G, et al. Correlation between the different $\mathrm{pH}$-metry scores in gastroesophageal reflux disease in children. Medicine (Baltimore) 2016;95:e3804.

40. Ristic N, Milovanovic I, Radusinovic M, et al. The comparative analyses of different diagnostic approaches in detection of gastroesophageal reflux disease in children. PLoS One 2017;12:e0187081.

41. Davis RD, Jr., Lau CL, Eubanks S, et al. Improved lung allograft function after fundoplication in patients with gastroesophageal reflux disease undergoing lung transplantation. J Thorac Cardiovasc Surg 2003;125:533-42.

42. Cantu E 3rd, Appel JZ 3rd, Hartwig MG, et al. J. Maxwell Chamberlain Memorial Paper. Early fundoplication prevents chronic allograft dysfunction in patients with gastroesophageal reflux disease. Ann Thorac Surg 
2004;78:1142-51; discussion 1151.

43. Mendez BM, Davis CS, Weber C, et al. Gastroesophageal reflux disease in lung transplant patients with cystic fibrosis. Am J Surg 2012;204:e21-6.

doi: $10.21037 / \operatorname{tgh} .2019 .08 .11$

Cite this article as: Woodley FW, Hayes D Jr, Kopp BT, Moore-Clingenpeel M, Machado RS, Nemastil CJ, Jadcherla S, Di Lorenzo C, Kaul A, Mousa H. Gastroesophageal reflux in cystic fibrosis across the age spectrum. Transl Gastroenterol Hepatol 2019;4:69.
44. Hayes D Jr, Kirkby S, S McCoy K, et al. Reduction of lipid-laden macrophage index after laparoscopic Nissen fundoplication in cystic fibrosis patients after lung transplantation. Clin Transplant 2013;27:121-5. 